\title{
SOCIAL READINESS FOR THE CONSEQUENCES OF THE PANDEMIC: SOCIOLOGICAL VIEW
}

\author{
Alexander V. Voytov \\ Volgograd State University, Volgograd, Russian Federation; \\ Volgograd Academy of the Russian Internal Affairs Ministry, Volgograd, Russian Federation \\ Dmitry V. Gladkov \\ Volgodonsk Branch of the Rostov Law Institute of the Ministry of Internal Affairs of Russia, \\ Volgodonsk, Russian Federation
}

\begin{abstract}
The speed of development and transformation of modern society is directly related to the conditions in which people live. The development of science and technology leads to transformations in social structures. The article analyzes the concept of social readiness in relation to the consequences of a number of social transformations, in particular, the coronavirus infection pandemic. Connections, interactions and relationships in all spheres of society have changed dramatically over the past year. These changes in the article are compared with the consequences of the Spanish Flu pandemic, which took place more than a hundred years ago. The article reveals the peculiarities of the perception of quarantinemeasures, distance learning and other consequences of self-isolation due to coronavirus infection by various categories of citizens, these conclusions are made based on the analysis of qualitative and quantitative sociological data. When disclosing the concept of «social readiness», attention is paid to both internal and external factors - factors of the social environment. Among the external factors, as an example, the measures introduced after the start of the pandemic by the governments of different countries, including the Russian Federation, are given in relation to various categories of citizens. Elderly citizens, the working-age population and students are the object of research of this article. The features of the perception of work in the online format, compulsory and voluntary self-isolation, distance education in departmental and civil universities by students are considered. The empirical basis of the work was semi-structured interviews with representatives of these social groups, a questionnaire survey among one of the categories of citizens, as well as a secondary analysis of sociological research. The conducted research allowed us to conclude that the age and perception of the threat of coronavirus infection for oneself are important internal factors affecting social readiness for the consequences of the pandemic; among the external factors, socialization agents and government measures have a great influence. Promising directions for further research are indicated.
\end{abstract}

Key words: social readiness, self-isolation, distance learning, social environment, work space, social practices, social interaction.

Citation. Voytov A.V., Gladkov D.V. Social Readiness for the Consequences of the Pandemic: Sociological View. Logos et Praxis, 2021, vol. 20, no. 2, pp. 143-153. (in Russian). DOI: https://doi.org/10.15688/lp.jvolsu.2021.2.16

УДК 316.473

ББК 60.524

\section{СОЦИАЛЬНАЯ ГОТОВНОСТЬ К ПОСЛЕДСТВИЯМ ПАНДЕМИИ: СОЦИОЛОГИЧЕСКИЙ ВЗГЛЯД}

\author{
Александр Владимирович Войтов
}

Волгоградский государственный университет, г. Волгоград, Российская Федерация; Волгоградская академия МВД России, г. Волгоград, Российская Федерация

\section{Дмитрий Викторович Гладков}

Волгодонский филиал Ростовского юридического института МВД России, г. Волгодонск, Российская Федерация 


\section{ИЗОЛЯЦИЯ В ОТКРЫТОМ ОБЩЕСТВЕ}

Аннотация. Скорость развития и трансформации современного социума напрямую связана с теми условиями, в которых живут люди. Развитие науки и техники ведет к трансформациям в социальных структурах. В статье анализируется понятие социальной готовности применительно к последствиям ряда социальных трансформаций, в частности - пандемии коронавирусной инфекции. Связи, взаимодействия и отношения во всех сферах жизни общества за последний год изменились кардинальным образом. Указанные изменения в статье сравниваются с последствиями пандемии «испанского гриппа», имевшими место более ста лет назад. На основании широкого спектра анализа качественных и количественных социологических данных раскрываются особенности восприятия различными категориями граждан карантинных мер, дистанционного обучения и других последствий самоизоляции, связанных с коронавирусной инфекцией. При раскрытии понятия «социальная готовность» обращается внимание как на внутренние факторы, так и на внешние - факторы социальной среды. Среди внешних в качестве примера приводятся меры, вводимые после начала пандемии правительствами разных стран, в том числе Российской Федерации, по отношению к различным категориям граждан. В качестве объекта исследования выступают пожилые граждане, трудоспособное население, а также студенческая молодежь. Рассматриваются особенности восприятия работы в онлайн-формате, обязательная и добровольная самоизоляция, дистанционное образование в ведомственных и гражданских вузах обучаемыми. Эмпирической основой работы выступили полуструктурированные интервью с представителями данных социальных групп, анкетный опрос среди одной из категорий граждан, а также вторичный анализ социологических исследований. Проведенное исследование позволило сделать вывод: важными внугренними факторами, влияющими на социальную готовность к последствиям пандемии, является возраст и восприятие угрозы коронавирусной инфекции лично для себя; среди внешних факторов большое влияние оказывают агенты социализации и меры государственного воздействия. Обозначаются перспективные направления для дальнейших исследований.

Ключевые слова: социальная готовность, самоизоляция, дистанционное обучение, социальная среда, рабочее пространство, социальные практики, социальное взаимодействие.

Цитирование. Войтов А. В., Гладков Д. В. Социальная готовность к последствиям пандемии: социологический взгляд // Logos et Praxis. - 2021. - Т. 20, № 2. - C. 143-153. - DOI: https://doi.org/10.15688/lp.jvolsu.2021.2.16

Трансформации, происходившие в мире до XX века, имели временную протяженность, измеряемую годами, десятилетиями, столетиями. Сохранялась преемственность в развитии сложных обществ, проявляющаяся в устойчивости цивилизаций при возникающих угрозах и вызовах. ХХ век с его научно-техническим прогрессом, демографическими взрывами, мировыми войнами и революциями был одним из выдающихся за последнюю тысячу лет. Однако по скорости преобразований во всех сферах жизни 2020 г. стал особенным из-за разразившейся пандемии (SARS-CoV-2) и «перестройки» образа жизни граждан по всему миру. Вследствие чего изменения произошли практически во всех секторах экономики: обвал международного туризма, но небольшой всплеск на рынке внутреннего туризма, уменьшение транспортных потоков, снижение потребления топлива, рост онлайн-торговых площадок и т. д. Изменилась культурная жизнь людей: вместо живых концертов и выставок - посещение онлайн-площадок, подписки на онлайн-кинотеатры, увеличение в 3 раза продаж книг через онлайнмагазины, переход на дистанционное образо- вание и др. Изменилась и политическая сфера: от граждан исходят новые требования к государству - защитить их жизни, их бизнес; новые формы протестов: «митинги игрушек», «овощные митинги», сходы, видеообращения медиков и т. д. Существуют и другие изменения в различных социальных институтах, включая семью, религию, СМИ, медицину, которые становятся объектом многочисленных исследований ученых по всему миру [Anwar et al. web; Cai 2020].

В данной статье социальные изменения не выступают объектом исследования, а обозначаются для демонстрации существенных перемен в жизни людей, выдвигая пандемию коронавируса в качестве более «сильного» детерминанта, даже в сравнении с пандемией, произошедшей около ста лет назад, получившей название «испанский грипп». Как отмечает российский микробиолог, полковник медицинской службы запаса, автор исследований по истории эпидемий чумы и других особо опасных инфекций М.В. Супотницкий: «Количество умерших от «испанки» было выше количества погибших на всех фронтах первой мировой войны. По-видимому, болело 
не меньше 550 млн человек, а погибло 2025 млн - более $1 \%$ всей численности населения планеты того времени» [Супотницкий 2006, 32]. На наш взгляд, благодаря упомянутому выше научно-техническому прогрессу и развитию информационных технологий коронавирусная инфекция, несмотря на меньшие человеческие жертвы, внесла больше изменений в социальные практики различных обществ на территории более 200 стран мира.

Вот почему внимание авторов статьи было сосредоточено на особенностях субъективного восприятия подобных изменений различными категориями населения, в том числе под целенаправленным воздействием государства на отдельные социальные группы.

Целью данной статьи является оценка и анализ социальной готовности различных категорий населения к последствиям пандемии. Прежде всего, необходимо определиться с понятием «социальная готовность», которая, на наш взгляд, должна включать такие компоненты как: социальные ожидания различных групп населения; определенное поведение, опосредуемое как формальными нормами и требованиями, выраженными в форме законов и предписаний, так и неформальными социальными установками, выраженными в оценке и восприятии социальной группой определенного поведения.

Таким образом, по нашему мнению, социальная готовность должна включать не только объективную реальность социальных практик, но и субъективную оценку переживаемого состояния. Субъективная оценка, по нашему мнению, должна включать элементы адаптационной готовности, выделяемые P.М. Шамионовым: представления личности о своих возможностях; представления о значимости сфер активности для самореализации [Шамионов 2012]; а также ряд элементов применительно к условиям пандемии коронавирусной инфекции (SARS-CoV-2): оценка опасности последствий пандемии лично для себя, своего здоровья и здоровья близких; имеющийся социальный опыт в периоды неопределенности.

Социальная готовность, как и социальная адаптация, приобретает особую актуальность для личности в условиях изменяющейся реальности современного мира, усиливающейся неопределенности, рискогенности и перманентных общественных изменений. С момента начала пандемии, весь мир находился в состоянии неопределенности. Как для человека, взаимодействующего с социумом, так и для гражданина, взаимодействующего с государством, вне зависимости от общества, в котором он проживает, внешняя среда могла предложить лишь два пути, две противоположные модели поведения, которые и выступили аттракторами в периоды неопределенности:

- полное отрицание угрозы и консерватизм в вопросах трансформации социальных отношений;

- добровольная самоизоляция и переход к новым форматам трудовой, учебной и досуговой деятельности.

Исходя из всего вышеперечисленного, предлагается понимать социальную готовность как комплексный, многокомпонентный феномен, обусловленный измененными социальными практиками, в которые включен индивид, его субъективные убеждения и поиски равновесия с социальной средой.

При изучении социальных практик, на наш взгляд, необходимо обратить внимание не столько на культурные и этнические компоненты, сколько на меры государственного воздействия, влияющие на поведение. Важно отметить, что правительства всех стран мира принимают различные меры: от сознательного игнорирования новой угрозы (правительство Швеции) до широких локдаунов, остановки целых секторов экономики и введения жестких карантинных мер для граждан. Правительство Российской Федерации в марте 2020 г. выделило ряд категорий граждан, в отношении которых предпринимались весьма конкретные решения [Указ Президента РФ от 25.03.2020 № 206... web; Указ Президента от 02.04.2020 № 239... web; Указ Президента от 28.04.2020 № 294... web]:

1. Трудоспособное население (временно неработающие) - изначально предоставлялись «каникулы» с сохранением заработной платы и последующим переводом на дистанционную форму работы.

2. Люди старшего возраста (старше 65 лет) - ограничения передвижений, а работающим пенсионерам - больничные. 
3. Школьники и студенческая молодежь - перевод на дистанционную форму обучения.

4. Родители детей, не достигших 16-летнего возраста - меры финансовой поддержки.

Для всестороннего анализа социальной готовности различных категорий населения к последствиям пандемии необходимо соотнести и выявить индикаторы четырех, указанных ранее элементов субъективной оценки ситуации, с мнением первых трех групп. Данные группы представляют различные возрастные когорты, а также предпочтительны по отношению к другим, поскольку меры воздействия оказали более пролонгированное действие, нежели разовые выплаты на детей в возрасте до 16 лет.

Методами, используемыми в данном исследовании, выступили полуструктурированные интервью с представителями данных социальных групп (по 10 интервью с представителями каждой категории), анкетный опрос студенческой молодежи (200 онлайнанкет для студентов, курсантов и слушателей в гражданских и ведомственных вузах г. Волгограда и г. Волгодонска, метод гнездовой выборки), а также вторичный анализ ряда исследований [Опросы... web; КоронаЗонд... web; Опрос студентов... web.]. В гайде полуформализованного интервью содержались вопросы о конкретных мерах, принятых в отношении респондента, а также самим респондентом после начала пандемии, как изменилась их жизнь; оценке ситуации и своего положения; перспективах и планах при дальнейшей стабилизации ситуации и т. д. Онлайн-анкеты содержали 12 вопросов о восприятии и оценке последствий пандемии лично для студентов и курсантов. В последствии результаты были сопоставлены с «интегральными индексами» и «трендиндексами» количественных опросов о влиянии пандемии на образ жизни граждан, их проблемы с финансами, работой, взаимоотношения с близкими и коллегами, психологические трудности.

При изучении первой группы (трудоспособного населения в возрасте от 23 до 60 лет) важно отметить одну особенность, выявленную в ходе интервью - чем ниже возраст респондентов, тем лучше они оценивают социальные последствия пандемии лично для себя, включая и возможность заболеть: «Мне кажется я уже переболел, почти как простуда, только запахов не чувствовал... Но дистанционно оказалось удобнее работать, по крайней мере нет необходимости тратить время и деньги на проезд» (Денис Б., наемный рабочий 28 лет). В данном случае ответ коррелирует с популярным ответом при количественном опросе трудоспособного населения, проведенный порталом «Работа в России»: Работа в удаленном режиме [Опросы... web] (время проведения 03.05.2020 - 09.06.2020, количество опрошенных онлайн - 55022 чел.) (рис. 1).

Другой респондент отметил: «Моя работа связана с командировками, встречами с

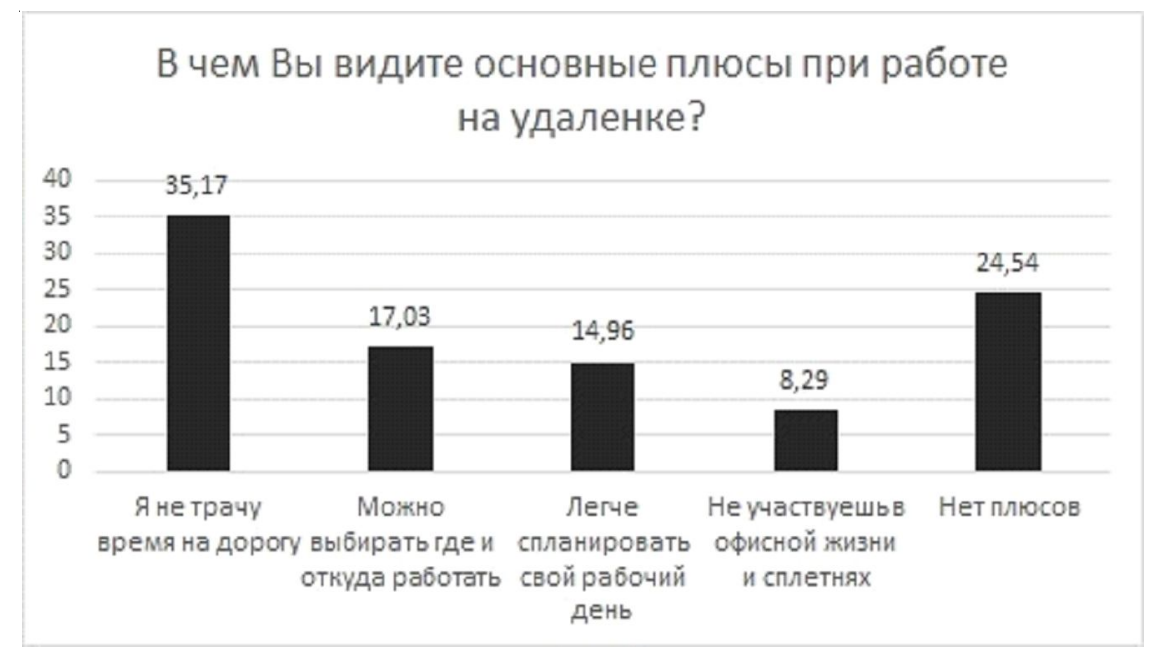

Рис. 1. Плюсы удаленной работы, в \% 
людьми и презентациями продукции. В прошлом году почти все делал через Skype и Zoom, возможности добавить красочную презентацию или видео облегчают работу. Надеюсь в этом году смогу еще и лично с клиентами встречаться» (Александр Б., торговый представитель 38 лет). Данные интервью коррелируют с данными социологических исследований [Опросы... web], согласно которым 21,1 \% респондентов признались, что им тяжело сосредоточиться дома, а эффективность работы снижается; $22,85 \%$ опрошенных отметили, что их отвлекают домочадцы (рис. 2).

Полученные нами данные подтверждают, что распространенным недостатком удаленной работы являются отвлекающие от работы факторы: «Из дома тяжеловато работать, особенно когда дети тоже дома - они думают, что у мамы выходные и постоянно лезут в экран» (Наталья В., педагог 43 года).

По общему мнению опрошенных из данной категории населения к последствиям пандемии можно привыкнуть при условии сохранения работы и дохода, а также общении с друзьями и родственниками онлайн. Важно отметить, что после мая 2020 г. около $60 \%$ опрошенных вернулись к «достаточно» привычному образу жизни, поскольку сферы торговли и производства продолжали работать: «Сельское хозяйство всегда должно работать, несмотря на эпидемии и другие ЧС. Люди всегда хотят кушать. Вот мы и работаем» (Сергей Р., фермер 40 лет).
Относительно работы в условиях пандемии мнения информантов нашего исследования полностью коррелируют с результатами исследования Е.П. Евдокимовой, которая отмечает происходящую трансформацию восприятия понятия "рабочее место и рабочее время», увеличение функциональной нагрузки на жилище, инициацию ревизии значимости непосредственных межличностных контактов в разных сферах жизнедеятельности [Евдокимова 2020].

Таким образом, социальная готовность работающего населения к последствиям пандемии определяется многими факторами, выделенными нами ранее, однако крайне важными оказываются два из них - представления личности о своих возможностях, включая возможности изменения графика трудовой деятельности и способа ее реализации, о возможности осваивать новые формы и форматы работы, получать дополнительное образование; а также представления о значимости сфер активности для самореализации. Данный компонент включает, прежде всего, трудовую активность, а соответственно лояльность работодателя к удаленной работе, возможности трансформации жилого пространства в «рабочее место», ненормированный характер «рабочего времени», сохранения уровня заработной платы, новые обязанности и т. д. Немаловажным фактором являются внешние социальные практики, а именно государственная политика в данном направлении, в част-

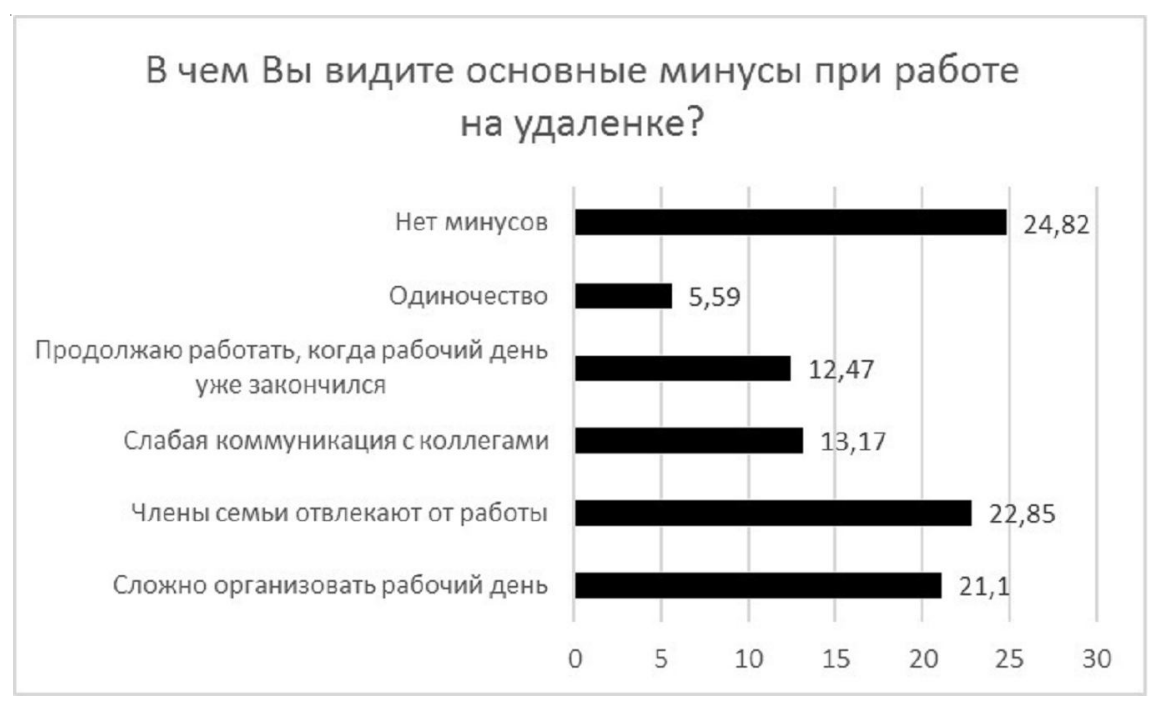

Рис. 2. Минусы удаленной работы, в \% 
ности отсрочки по налогам для малого и среднего бизнеса, по страховым взносам для микропредприятий, для бизнеса в выплате кредитов; возможность бесплатно пролонгировать кредиты физическим лицам.

Другой изучаемой категорией населения стали представители «старшего поколения» - лица старше 65 лет (как работающие, так и не работающие пенсионеры). В отношении данной категории граждан дольше всего действовали ограничительные меры больничные [Постановление Правительства РФ от 01.04.2020 года № 402... web] (в отсутствие болезни) и ряд ограничений, например, в Москве и некоторых других регионах временно не действовали льготы на проезд в общественном транспорте. Важно отметить, что ограничения в разных регионах носили как рекомендательный, так и строгий, обязательный характер, включая и обязательные меры по самоизоляции. При этом данное понятие использовалось не в дефиниции Всемирной Организации Здравоохранения, где самоизоляция - важная профилактическая мера, принимаемая самостоятельно людьми с симптомами COVID-19 для предупреждения заражения окружающих, в том числе членов семьи.

В России под самоизоляцией понимались также ограничения передвижения, которые могут быть как добровольными и рекомендованными на фоне опасности заражения вирусным заболеванием, так и принудительными, введенными в связи с объявлением чрезвычайной ситуации или введением режима повышенной готовности, когда граждане должны ограничить свои передвижения и контакты для сдерживания эпидемии.

Большинством граждан РФ самоизоляция воспринимается как социальная изоляция или отторжение человека / социальной группы от окружающих людей в результате прекращения или резкого сокращения социальных контактов и отношений. Информанты заявляли об этом в интервью: «Да, мы с мужем на самоизоляции, но иногда приезжают дети, оставляют внуков... гипермаркет посещаем пару раз в неделю... с друзьями и знакомыми стали реже встречаться - где-то раз в две недели». Единственное ограничение, отмеченное информантом, - перестали посещать культур- но-массовые мероприятия: «В театр не ходим, на концерты. В кино не ходим... да мы и до этого не ходили» (Татьяна Г., работающий пенсионер 71 год).

Было выявлено диаметрально противоположное отношение к самоизоляции. Так, часть информантов самоизоляцию воспринимают довольно позитивно, они находят в данной ситуации свои плюсы: «Очень хорошо на самоизоляции - много дел по дому успела сделать, которые до этого постоянно не успевала, начала (вновь) читать» (Татьяна Г., работающий пенсионер 71 год).

Другие негативно оценивают ситуацию: «Работы стало меньше, а как я без работы?! Денег не хватает, все дорого - в магазине, в аптеке...» (Вера Н., работающий пенсионер (коммерция) 60 лет).

Также среди информантов присутствовало мнение, что их жизнь особо не изменилась: «Как жили, так и живем... домашними делами занимаемся» (Тамара В., пенсионер 69 лет). «По телевизору постоянно про эту пандемию, но я думаю ничего страшного, мы-то куда выходим?!» (Тамара В., пенсионер 69 лет).

Однако были и те информанты, которые достаточно серьезно относятся к рекомендациям ВОЗ и министерства здравоохранения РФ: «Я ни с кем не встречаюсь лично - дети привозят продукты и оставляют их у двери, где я оставляю гостинцы и подарки для внуков... Общаемся по интернету, skype и т. д.» (Михаил Н., неработающий пенсионер 65 лет).

Относительно данной категории граждан социальная готовность обеспечивается как внутренними мотивами, связанными с высокой опасностью заболеть новой болезнью и тяжестью ее последствий, так и внешними широким спектром мер государственного воздействия, в том числе через средства массовой информации - телевидение. В то же время, государство действует не только запретными мерами, но и мерами поддержки, что также было отмечено некоторыми информантами: «Пока продлевают режим больничных для 65+, я буду дома» (Олег Я., работающий пенсионер 66 лет); «Я хожу иногда на работу, когда завал или попросят, но из-за продлений больничных для пенсионеров, работа на эти полгода стала хобби, могу полениться и не 
прийти» (Лариса В., работающий пенсионер 70 лет). Относительно внутренней мотивации, обеспечивающей социальную готовность «старшего поколения» к последствиям пандемии примечателен ответ одного информанта: «Мы воспитаны при коммунизме, когда сказано - сделано. Если вводят маски - надо носить маски, если нельзя выходить лишний раз из дома - не будем» (Владимир В., пенсионер 72 года). Тем самым мы отмечаем воздействие первичной социализации на внутренние мотивы граждан, сформированные в условиях социалистического государства, когда решения государственного аппарата подлежат обязательному принятию и исполнению.

В результате анализа ответов информантов можно выделить три категории среди старшего поколения по критерию воздействия самоизоляции на образ жизни, а соответственно на социальную готовность к последствиям пандемии:

1) те, чей образ жизни не изменился: а) те, кто, рискуя, не уходит на самоизоляцию (продолжают работать в коммерческой сфеpe); б) те, кто и до пандемии вел изолированный образ жизни, и самоизоляцию воспринял нормально, а возможно не почувствовал ее;

2) те, кто, понимая угрозу для своего здоровья, самостоятельно принял решение о самоизоляции;

3) работающие пенсионеры, которые вынуждены изменить привычный образ жизни они не ходят на работу, теряют социальные связи в профессиональной среде и выходят из положения двумя способами: женщины нахо- дят себя в домашних заботах, встречах с внуками, рукоделии; мужчины же реже находят занятие дома (за исключением частного дома) и все больше внимания уделяют просмотру телевидения (реже интернет).

Таким образом, обладание большим социальным опытом в периоды неопределенности, а также осознание реальности угрозы нового вируса для себя и близких меняют социальные практики пожилых людей в большей степени, нежели других категорий населения. Старшее поколение дисциплинированно относится к угрозам и последствиям пандемии и в целом готово к самоизоляции, однако многие ждут поддержку (не только материальную) от государства и близких в таких условиях неопределенности.

Крайне неоднозначной категорией для анализа выступила студенческая молодежь. Диаметрально противоположные мнения были выявлены относительно восприятия последствий пандемии для себя лично (рис. 3).

В результате дальнейшего анализа была выявлена причина столь разных оценок - признак подведомственности образовательного учреждения: так $85 \%$ оценивших последствия как «полностью положительные» и «скорее положительные» получают образование в гражданских вузах. Среди высказываний информантов примечательным является следующее: «Дистанционное образование позволило участвовать в международных конференциях и других мероприятиях, а также параллельно с обучением заниматься хобби» (Анастасия Т., 19 лет). 80 \% курсантов и слушате-

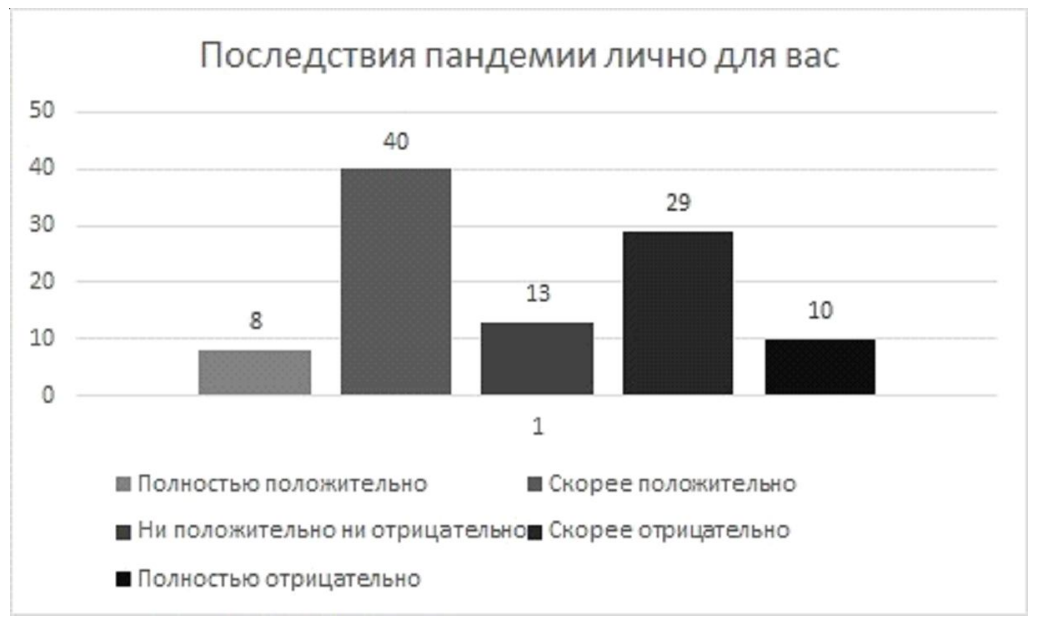

Рис. 3. Оценка последствий пандемии для себя, в \% 


\section{ИЗОЛЯЦИЯ В ОТКРЫТОМ ОБЩЕСТВЕ}

лей образовательных учреждений МВД, участвовавших в исследовании, оценивают последствия пандемии «скорее отрицательно» и «полностью отрицательно». Некоторые информанты отмечают отсутствие практических занятий и несовершенство дистанционного формата: «При очном формате обучения знаний больше остается и есть возможность изучать практические дисциплины, а также огневая и физическая подготовка, которая практически невозможна на удаленке» (Игорь С., 20 лет); «Скорее недоволен, так как дистанционное обучение не было эффективным, а наряды и дежурства никто не отменял» (Федор Г., 19 лет).

В результате анализа полуформализованных интервью была выявлена особенность дистанционного образования, которую отмечали все информанты - отсутствие привычного контроля за работой студентов как на лекциях, так и на семинарских занятиях, ответственность переносилась на самодисциплину студентов, которые находили инновационные способы работы на занятиях: «Мои одногруппники работали на нескольких устройствах одновременно - телефон, компьютер, в том числе на зачетах и экзаменах» (Даниил Л., 21 год); «Те, кто были не готовы, писали в чат, что у них не работает микрофон или камера, те кто прогуливал - ссылались на проблемы с подключением» (Ольга Б., 20 лет). Подобную проблему затрагивали в своем исследовании, касающемся истории развития онлайн-обучения и возможных путей трансформации, американские исследователи Сингх и Турман [Singh, Thurman 2019].
В данных условиях важна эффективная практическая реализация системы организации ДО в вузах при обучении студентов в условиях вирусной пандемии, которая оказывается возможной при наличии заранее подготовленной телекоммуникационной и кадровой инфраструктуры [Абрамян, Катасонова 2020].

Данные позиции отражены также в результатах совместного проекта Института образования НИУ ВШЭ, Центра внутреннего мониторинга НИУ ВШЭ и Института образования ТГУ [Опрос студентов... web] (период исследования: 24.05.2020-01.06.2020 выборка 23314 чел.) (рис. 4).

Кроме того, примечательным является кейс, о котором рассказал один из информантов, по его словам, инициативная группа студентов обратилась к руководству факультета с просьбой снизить стоимость обучения, поскольку занятия проводятся в дистанционной форме, что не предполагается «договором», в результате чего очные занятия для данного факультета были возобновлены.

Таким образом, можно отметить, что созданные вузами и государством условия для дистанционного образования в отсутствии у курсантов и студентов должного уровня внутренней мотивации и готовности не создали предпосылки к формированию социальной готовности к последствиям пандемии. Также молодежь в большей мере нарушала установленные правила самоизоляции, встречаясь группами, не соблюдая масочный режим и социальную дистанцию, что во многом объясняется малым социальным опытом в периоды неопределенности, а также недооценкой

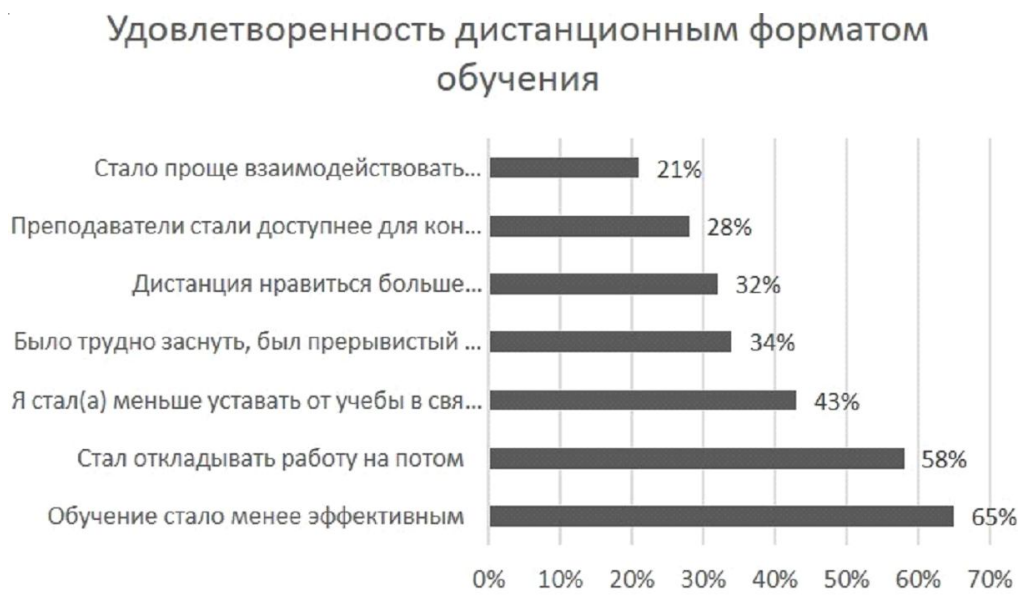

Рис. 4. Оценка дистанционного обучения, в \% 
угрозы в лице нового вируса. В данных условиях, а также при наличии выделяемых [Матвиенко 2016] социально-экономических, демографических, политических, коммуникационных и некоторых факторов внешнего воздействия, вероятна протестная (оппозиционная) активность молодежи, с крайними ее проявлениями в форме экстремизма.

Рассмотренные категории населения и их социальная готовность к последствиям пандемии позволяют сделать ряд выводов:

- возраст, а, соответственно, имеющийся социальный опыт в периоды неопределенности имеют определяющее воздействие на социальную готовность к последствиям пандемии. Дополнительным воздействующим фактором выступает субъективное восприятие реальной угрозы для жизни и здоровья граждан, чья связь с возрастом респондентов также была зафиксирована;

- меры государственного воздействия воспринимаются гражданами как необходимые и своевременные, хотя и требуют детальной проработки и уточнений;

- последствия пандемии, включая режим самоизоляции и дистанционное обучение, трансформировали социальные практики всех категорий граждан, перенеся в онлайн-сферу разнообразные социальные взаимодействия и расширив функциональную нагрузку жизненного пространства граждан. Появилось несколько иное понимание своего социального окружения, включая отношения с родственниками и коллегами.

Несмотря на проведенный анализ, не были учтены другие важные категории граждан, у которых существует корпоративная культура: медицинские работники, работники образовательных организаций, государственные служащие и военнослужащие, сотрудники IT-компаний, сферы услуг и др., что позволило бы взглянуть на ситуацию под другим углом и выявить иные факторы и признаки социальной готовности к последствиям пандемии, которые фрагментарно изучаются как отечественными [Абрамян, Катасонова web; Kozlovskaya et al. 2020], так и зарубежными исследователями [Segal et al. 2020; Dhawan 2020]. Изучение корпоративной культуры вышеупомянутых социально-профессиональных групп формирует как формальные, так и не- формальные отношения в данных сообществах, а соответственно восприятие и социальную готовность к последствиям пандемии. Также важно отметить, что вызовы и угрозы нового времени трансформируют социальные практики в большей мере, нежели идеологические и пропагандистские меры.

\section{СПИСОК ЛИТЕРАТУРЫ}

Абрамян, Катасонова web- Абрамян Г.В., Катасонова Г.Р. Особенности организации дистанционного образования в вузах в условиях самоизоляции граждан при вирусной пандемии [Современные проблемы науки и образования. 2020. № 3] // https://science-education.ru/ $\mathrm{ru} /$ article/view?id $=29830$.

Евдокимова 2020 - Евдокимова Е.П. Трансформация повседневных практик городского населения России в условиях пандемии COVID19 // Социология и право. 2020. № 4. С. 32-41.

КоронаЗонд... web - КоронаЗонд. Ежедневные опросы ФОМ. 2021 [Сайт ФОМ] // https://fomru. sharepoint.com/:x:/s/inFOM/EUuLyWmcTANP qsNzbERFxuEBMNPmEXBiHUXUm3OZm4 VKhA?rtime $=$ KqAR6GXQ2Eg.

Матвиенко 2016 - Матвиенко Е.А. Экстремизм как социальная болезнь: причины и профилактика // Вестник Волгоградской академии МВД России. 2016. № 3 (38). С. 159-163.

Опрос студентов... web-Опрос студентов российских вузов об условиях дистанционного обучения [Сайт Центра внутреннего мониторинга] // https://cim.hse.ru/covidsurvey.

Опросы... web - Опросы [Портал «Работа в России»] $/ / \mathrm{https}: / /$ trudvsem.ru/information/questionnaire/list.

Постановление Правительства РФ от 01.04.2020 года № 402... web - Постановление Правительства Российской Федерации от 01.04.2020 № 402 “Об утверждении Временных правил оформления листков нетрудоспособности, назначения и выплаты пособий по временной нетрудоспособности в случае карантина застрахованным лицам в возрасте 65 лет и старше" // http://publication.pravo.gov.ru/Document/ View/0001202004020018.

Супотницкий 2006 - Супотниикий М.В. Пандемия «Испанки» 1918-1920 гг. в контексте других гриппозных пандемий и «птичьего гриппа» // Медицинская картотека. 2006. № 11. С. 31-34.

Указ Президента от 02.04.2020 № 239... web - Указ Президента РФ от 2 апреля 2020 г. № 239 «О меpax по обеспечению санитарно-эпидемиологического благополучия населения на территории Российской Федерации в связи с рас- 
пространением новой коронавирусной инфекции (COVID-19)» // http://base.garant.ru/ $73835022 /$.

Указ Президента РФ от 25.03.2020 № 206... web Указ Президента РФ от 25 марта 2020 г. № 206 «Об объявлении в Российской Федерации нерабочих дней» // http://base.garant.ru/73793643/.

Указ Президента от 28.04.2020 № 294... web - Указ Президента РФ от 28 апреля 2020 г. № 294 «О продлении действия мер по обеспечению санитарно-эпидемиологического благополучия населения на территории Российской Федерации в связи с распространением новой коронавирусной инфекции (COVID-19)» // http://base. garant.ru/73964751/.

Шамионов 2012 - Шамионов Р.М. Соотношение адаптационной готовности и социальной активности личности // Теоретическая и экспериментальная психология. 2012. Т. 5, № 2. С. 72-80.

Anwar et al. web - Anwar A., Malik M., Raees V., Anwar A. Role of Mass Media and Public Health Communications in the COVID-19 Pandemic [Cureus. 2020. № 12 (9)] // https://www. researchgate.net/publication/344307068_Role_ of_Mass_Media_and_Public_Health_ Communications in the COVID-19 Pandemic.

Cai web - Cai H. Sex Difference and Smoking Predisposition in Patients with COVID-19 [Lancet Respiratory Medicine. 2020. № 84 (4)] // https://www.researchgate.net/publication/ 346585660_Sex-based_clinical_and immunological_differences_in_COVID-19.

Dhawan 2020 - Dhawan S. Online Learning: A Panacea in the Time of COVID-19 Crisis // Journal of Educational Technology Systems. 2020. Vol. 49(1). P. 5-22.

Kozlovskaya et al. 2020 - Kozlovskaya L., Piniaeva A., Ignatyev G., Selivanov A., Shishova A., KovpakA., Gordeychuk I., Ivin Y., Berestovskaya A., Prokhortchouk E., Protsenko D., Rychev M., Ishmukhametov A. Corrigendum to Isolation and Phylogenetic Analysis of SARS-CoV-2 Variants Collected in Russia During the COVID-19 Outbreak // International Journal of Infectious Diseases. 2020. № 99. P. 40-46.

Segal et al. 2020 - Segal D., Rotschield J., Ankory R., Kutikov S., Moaddi B., Verhovsky G., Benov A., Twig G., Glassberg E., Fink N., Bader T., Karp E. Measures to Limit COVID-19 Outbreak Effects AmongMilitaryPersonnel:PreliminaryData//Military Medicine. 2020. № 185(9-10). P. 1624-1631.

Singh, Thurman 2019 - Singh V., Thurman A. How Many Ways Can We Dene Online Learning? A Systematic Literature Review of Denitions of Online Learning (1988-2018) // American Journal ofDistance Education. 2019. № 33 (4). P. 289-306.

\section{REFERENCES}

Abrahamyan G.V., Katasonova G.R., 2020. Features of the Organization ofDistance Education in Universities in the Conditions of Self-Isolation of Citizens During a Viral Pandemic. Sovremennyye problemy nauki $i$ obrazovaniya, no. 3. URL: https://scienceeducation.ru/ru/article/view?id=29830.

Evdokimova E.P., 2020. Transformation of Everyday Practices of the Urban Population of Russia in the Context of the COVID-19 Pandemic. Sotsiologiya i pravo, no. 4, pp. 32-41.

Crown Probe. FOM daily polls. 2021. URL: https:// fomru.sharepoint.com/:x:/s/inFOM/EUuLyWmc TANPqsNzbERFxuEBMNPmEXBiHUXUm3 OZm4VKhA?rtime=KqAR6GXQ2Eg.

Matvienko E.A., 2016. Extremism as a Social Disease: Causes and Prevention. Vestnik Volgogradskoy akademii MVD Rossii, no. 3 (38), pp. 159-163.

Survey of Students of Russian Universities on the Conditions of Distance Learning 2021. URL: https://cim.hse.ru/covidsurvey.

Polls. Portal “Work in Russia”. URL: https://trudvsem. ru/information/questionnaire/list.

Supotnitskiy M.V., 2006 The Spanish Flu Pandemic 1918-1920 in the Context of Other Influenza Pandemics and Avian Influenza. Meditsinskaya kartoteka, no. 11.pp. 31-34.

Resolution of the Government of the Russian Federation of 01.04.2020 No. $402 « O n$ Approval of the Temporary Rules for the Issuance of Certificates of Incapacity for Work, the Appointment and Payment of Benefits for Temporary Incapacity for Work in the Event of Quarantine to Insured Persons Aged 65 and Over». URL: http://publication.pravo.gov.ru/ Document/View/0001202004020018.

Decree of the President of the Russian Federation of 02.04.2020 No. 239 "On Measures to Ensure the Sanitary and Epidemiological Well-Being of the Population on the Territory of the Russian Federation in Connection with the Spread of a New Coronavirus Infection (COVID-19)». URL: http://base.garant.ru/73835022/.

Decree of the President of the Russian Federation of March 25, 2020 No. 206 «On the Announcement of Non-Working Days in the Russian Federation». URL: http://base.garant.ru/73793643/.

Decree of the President of the Russian Federation of 28.04.2020 No. 294. "On the Extension of Measures to Ensure the Sanitary and Epidemiological Well-Being of the Population on the Territory of the Russian Federation in Connection with the Spread of a New Coronavirus Infection (COVID-19)». URL: http://base.garant.ru/73964751/. 
Shamionov R.M., 2012. The Ratio of Adaptive Readiness and Social Activity of the Individual. Teoreticheskaya i eksperimental'naya psikhologiya, vol. 5, no. 2, pp. 72-80.

Anwar A., Malik M., Raees V., Anwar A., 2020. Role of Mass Media and Public Health Communications in the COVID-19 Pandemic. Cureus, no. 12 (9). URL: https://www.researchgate.net/publication/ 344307068 Role of Mass Media and Public Health Communications in the COVID-19 Pandemic.

Cai H., 2020. Sex Difference and Smoking Predisposition in Patients with COVID-19. Lancet Respiratory Medicine, no. 84 (4). URL: https://www.researchgate.net/publication/ 346585660_Sex-based_clinical_and immunological_differences_in_COVID-19.

Dhawan S., 2020. Online Learning: A Panacea in the Time ofCOVID-19 Crisis. Journal of Educational Technology Systems, vol. 49 (1), pp. 5-22.
Kozlovskaya L., Piniaeva A., Ignatyev G., Selivanov A., Shishova A., Kovpak A., Gordeychuk I., Ivin Y., Berestovskaya A., Prokhortchouk E., Protsenko D., Rychev M., Ishmukhametov A., 2020. Corrigendum to Isolation and Phylogenetic Analysis of SARSCoV-2 Variants Collected in Russia During the COVID-19 Outbreak. International Journal of Infectious Diseases, no. 99, pp. 40-46.

Segal D., Rotschield J., Ankory R., Kutikov S., Moaddi B., Verhovsky G., Benov A., Twig G., Glassberg E., Fink N., Bader T., Karp E., 2020. Measures to Limit COVID-19 Outbreak Effects Among Military Personnel: Preliminary Data. Military Medicine, no. 185 (9-10), pp. 1624-1631.

Singh V., Thurman A., 2019. How Many Ways Can We Dene Online Learning? A Systematic Literature Review of Denitions of Online Learning (19882018). American Journal of Distance Education, no. 33 (4), pp. 289-306.

\section{Information About the Authors}

Alexander V. Voytov, Master's Student, Department of Philosophy, Volgograd State University, Prosp. Universitetsky, 100, 400062 Volgograd, Russian Federation; Candidate of Sciences (Sociology), Associate Professor, Department of Philosophy, Volgograd Academy of the Russian Internal Affairs Ministry, Istoricheskaya St, 130, 400089 Volgograd, Russian Federation, alexvoy@mail.ru, https://orcid.org/0000-0002-9740-8218

Dmitry V. Gladkov, Senior Lecturer, Department of Tactical and Special Training, Volgodonsk Branch of the Rostov Law Institute of the Ministry of Internal Affairs of Russia, Stepnaya St, 40, 347360 Volgodonsk, Russian Federation, dmitri-don-55@mail.ru, https://orcid.org/0000-0001-5141-4279

\section{Информация об авторах}

Александр Владимирович Войтов, магистрант кафедры философии, Волгоградский государственный университет, просп. Университетский, 100, 400062 г. Волгоград, Российская Федерация; кандидат социологических наук, доцент кафедры философии, Волгоградская академия МВД России, ул. Историческая, 130, 400089 г. Волгоград, Российская Федерация, alexvoy@mail.ru, https://orcid.org/0000-0002-9740-8218

Дмитрий Викторович Гладков, старший преподаватель кафедры тактико-специальной подготовки, Волгодонский филиал Ростовского юридического институга МВД России, ул. Степная, 40, 347360 г. Волгодонск, Российская Федерация, dmitri-don-55@mail.ru, https://orcid.org/0000-0001-5141-4279 